\title{
Infections Among Cruise Passengers
}

\section{(A Legionella-like Organism?)}

In April 1984, 430 people went on a cruise from Gothenburg to Bordeaux, Lisbon, Cádiz, Casablanca, Lanzarote, Madeira, Cherbourg, London, and back to Gothenburg. The cruise liner was a fairly old-fashioned ship, e.g. air conditioning was only present in the saloon, and not in the cabins.

During the cruise many of the passengers were taken ill. Six of them needed to be hospitalized on their return to Gothenburg as they could not manage at home. In two of these patients, antibodies to Legionella pneumophila at a titer of 64 and 32, respectively, were found using an indirect immunofluorescence technique. In view of these findings, the rest of the travellers who lived in Gothenburg were invited for medical examination.

A total of 52 people, 23 men and 29 women (22-80 years old; $70 \%$ were more than 60 years old) were examined at the Department of Infectious Diseases in Gothenburg. They had all been ill as a result of the cruise. The predominant symptoms were cough $(90 \%)$, hoarseness $(50 \%)$, fever more than $39^{\circ} \mathrm{C}(50 \%)$, fatigue $(40 \%)$, diarrhoea $(40 \%)$ and muscular pains $(20 \%)$. Slightly increased amino transferase levels were found in $20 \%$, and $20 \%$ had haematuria. Full physical examination revealed only bronchitis in two patients, and X-ray showed pleuritis in one patient.

Bacterial cultivation on nasopharyngeal aspirate revealed normal flora of the upper respiratory tract. L. pneumophila could not be detected by culture or direct immunofluorescence.

Analysis of paired serum samples displayed a significant increase (four-fold or more) in titers of antibodies to the following viral antigens: influenza A virus: one patient; influenza B virus: four patients; parainfluenza type 3 virus: two patients; respiratory syncytial virus: one patient; Epstein-Barr virus: three patients; and cytomegalovirus: one patient. None of the patients showed a significant increase in titers of antibodies to Mycoplasma pneumoniae, Chlamydia psittaci, parainfluenza type 2 virus, adenovirus or coxsackievirus. Two patients had a $L$. pneumophila serogroup 1 antibody titer of 256 , four patients a titer of
128 , two patients a titer of 64 and 13 patients a titer of 32 . A significant antibody titer increase was seen in one patient.

A sporadic increase in antibody titers to different viral antigens is to be expected when many people stay together in a limited area. Although the low titers, 32 and 64, of antibodies to $L$. pneumophila are not diagnostic, they are above the normal level in Gothenburg $(<16)$. Antibodies to $L$. pneumophila serogroups $2-6, L$. bozemanii, $L$. longbeachae and $L$. micdadei were also sought, but the results did not reveal any further information. No correlation was found between antibody titers to different viruses and Legionella indicating cross-reactions. It was not possible to search the boat for a possible source of infection, but the ventilation and water systems on board could have been reservoirs for Legionella.

Diarrhoea was more frequent in patients in whom Legionella antibodies were found, while fever and muscular pain were more frequent in patients in whom Legionella antibodies were not found. With regard to the other symptoms and the duration of illness, there was no difference between the groups.

In addition to the illnesses expected on a cruise like this, something extraordinary also happened here. As yet, it is not known which infectious agent was involved. It might have been a microorganism which is antigenically related to Legionella. We would be grateful for diagnostic suggestions from any readers who may recognize the pattern.

\section{E. Berntsson, H. Hogevik, G. Lidin-Janson, S. Jeansson, I. Kallings}

Elisabeth Berntsson, M.D., Department of Clinical Bacteriology, University of Göteborg, Guldhedsgatan 10, S-413 46 Göteborg;

Harriet Hogevik, M.D., Gunilla Lidin-Janson, M.D., Department of Infectious Diseases, University of Göteborg, Östra Sjukhuset, S-416 85 Göteborg;

S. Jeansson, M.D., Department of Clinical Virology, University of Göteborg, Guldhedsgatan 10, S-413 46 Göteborg;

Ingegerd Kallings, M.D., Department of Bacteriology, National Bacteriological Laboratory, S-105 21 Stockholm. 